\title{
Responsabilidad ética de educadores y educandos desde una perspectiva humanista
}

\author{
Ethical Responsibility of Teachers and Students from a Humanistic Perspective
}

\author{
Luis Guillermo Barrantes Montero' \\ Escuela de Literatura y Ciencias del Lenguaje \\ Universidad Nacional \\ Heredia, Costa Rica \\ luisba66@yahoo.es
}

Recibido 17 de octubre de 2012 • Corregido 02 de febrero de 2013 • Aceptado 13 de marzo de 2013

Resumen. Esta obra es una reflexión sobre la necesidad de la responsabilidad ética en centros de educación superior, tanto por profesores y alumnos. Los objetivos son dos: Primero, identificar las razones del comportamiento corrupto en algunos graduados universitarios, una vez que entran en la mano de obra o servicio público. En segundo lugar, representar formas mediante las cuales la gente educada puede formar y promover una cosmovisión ética en la sociedad. Se concluye que la educación vista como un privilegio y como un compromiso induce la virtud de gratitud y, en consecuencia, un comportamiento ético y humanista.

Palabras claves. Cosmovisión, educación superior, humanismo, responsabilidad ética, valores, Revista Electrónica Educare, Costa Rica.

Abstract. This paper provides some considerations on the importance of ethical responsibility in higher education institutions for both teachers and students. Its purpose is to identify the causes of corrupt behavior in some university graduates once they become part of the labor force or public service. It also points out some ways through which an ethical worldview can be formed and promoted in society. It is concluded that education, seen as a privilege and as a commitment, leads to the virtue of gratitude and, consequently, to a humanistic ethical behavior.

Keywords. Worldview, higher education, humanism, ethical responsibility, values, Educare Electronic Journal, Costa Rica.

1 Posee una maestría Profesional en la Enseñanza del Inglés por la Universidad de Costa Rica (2006). Cuenta además con una licenciatura en Traducción Inglés-Español por la Universidad Nacional, Costa Rica (1996), una licenciatura en Teología por la Universidad Francisco Marroquín, Guatemala (1992) y un bachillerato en Filosofía por la Universidad Francisco Marroquín, Guatemala (1989). Durante diecinueve años se ha desempeñado como docente de inglés y de español como segunda lengua y actualmente coordina el Departamento de Cursos de Servicio en la Universidad Nacional, Costa Rica. Ha realizado ponencias en congresos internacionales y varios de sus artículos y ponencias han sido publicados en revistas como EDUCARE y LETRAS, ambas de la Universidad Nacional. 
URL: http://www.una.ac.cr/educare

CORREO: educare@una.cr

\section{Introducción}

Aun cuando en la actualidad se da por sentado, el acceso a la educación sigue siendo privilegio de una pequeña parte de la población mundial. De hecho, la democratización del conocimiento no es asunto de discusión en la mayoría de las sociedades. Sin embargo, ya sea aduciendo principios religiosos o solo por prácticas tradicionales discriminatorias -en torno a las cuales algunos grupos humanos fundamentan sus instituciones de convivencia-, la verdad es que la información, el aprendizaje y la formación del pensamiento crítico no están disponibles para cualquier persona. En otras palabras, la educación es, en sí misma, "un motivo de exclusión" (Bautista, 2006, p. 3).

En las sociedades occidentales, lejos de considerarse un privilegio, la educación es un derecho. La mayoría de los gobiernos, los empleadores privados y la gente común concuerdan en que el conocimiento, así como el acceso a él, debe estar disponible para todo el mundo como la manera de formar mejores ciudadanos, consumidores más inteligentes, trabajadores cualificados y buenos vecinos. Lo anterior, incluso si se tiene en cuenta la creciente ambigüedad con respecto a la educación como un bien privado o público². Además, las redes sociales han promovido la transparencia y la diafanidad en las acciones de las autoridades y motivan a la gente común para que expresen su opinión sobre casi cualquier tema. Pocos son los asuntos, si los hay, de los cuales la gente común no tiene noticia o incluso no se atrevería a comentar abiertamente mediante la web. "Wikileaks", por ejemplo, ha publicado informaciones comprometedoras para quienes estelarizan tales noticias.

Ciertamente, conviene hacer aquí una distinción entre educación formal e informal, con el fin de enfocar mejor en el ámbito de este documento. Por educación formal se entiende la sistematización de los conocimientos adquiridos por la humanidad a lo largo de la historia y de los que las nuevas generaciones disponen gracias, tanto al sistema público como al privado. Sin embargo, como lo afirman Escofet, García y Gros (2011), en virtud de las tecnologías de la información, los límites entre la educación formal, no formal e informal son cada día más borrosos.

A diferencia del pasado y, como una contribución postmoderna contra los positivistas, el conocimiento ya no es un producto completo y acabado, sino una propuesta de significaciones con sentido, según la interpretación que cada quien haga de ellas en un momento dado de la historia. Valga para ilustrar, el "hombre Marlboro" y la reacción que suscitó en varones jóvenes hace varias décadas en todas partes donde fue anunciado. Hoy, las fábricas de cigarrillos y sus anunciantes deben recurrir a significantes más actualizados y a figuras más atractivas para promocionar su producto, puesto que el arrogante valiente que enciende un cigarrillo como signo de poder y audacia ha perdido su valor como significante para el presente.

Por otro lado, la educación informal se compone de todos los medios por los que la información se encuentra disponible para los individuos, ya sea en casa, en las calles o en la red. Sin embargo, la educación, en cualquiera de sus formas, pretende ayudar a los seres humanos a

2 Respecto de la educación como bien privado, administrado de manera pública, privada o mixta, véase el artículo de Acevedo y Rodríguez (2008). 
resolver sus problemas. Como lo afirma Bautista, "es parte del proceso de la perfección humana el poseer esa capacidad" (Bautista, 2006, p. 3).

El propósito de este documento consiste en reflexionar acerca de la educación formal superior, que es al mismo tiempo un derecho y un privilegio, y del compromiso de gratitud que ello supone tanto para educadores como para estudiantes. La pertinencia de esta reflexión se evidencia en que, cada vez que alguien se gradúa de la Universidad, suele considerarse que ya cuenta con la suficiente preparación en todas las dimensiones de su vida para enfrentar sus constantes desafíos: acaso se suponen de algún modo también inoculados para no sucumbir ante las tentaciones de la corrupción.

No obstante, una mirada a la realidad de muchos profesionales en términos de comportamiento ético será suficiente para concluir que este supuesto es irreal. Se requiere, por tanto, de parte de docentes y alumnos, la procura de una rendición de cuentas cotidiana ante sí mismos y ante toda la sociedad, para reafirmar su compromiso de no desviarse de alguna manera. Se propone el entrenamiento y cultivo de una cosmovisión ética durante los procesos de formación inicial y permanente para que los profesionales orienten sus esfuerzos en mejora de la calidad de vida para sí y para toda la sociedad. Como señalan Pasmanik and Winkler (2009), en la ética de la educación superior se identifican dos tendencias: una proviene del hecho de ser miembro de la Universidad e impregna toda la experiencia y su justificación se sustenta en la responsabilidad del individuo con la sociedad. La otra es la formación explícita en materia de ética profesional, un proceso que debe comenzar en los primeros años de la carrera y luego continuar a lo largo de todo el proceso.

Lo anterior expresa la conveniencia de insistir en que la formación ética de los profesionales es un proceso continuo y atento a las exigencias de cada época y de cada coyuntura cultural, social, política y económica.

\section{Pros y contras de la diversificación de centros de educación superior y la proliferación de nuevos profesionales}

Las sociedades modernas, incluso en los países en desarrollo, han realizado grandes inversiones en educación superior, tanto por parte de los gobiernos como de la iniciativa privada. Con ello, las macroeconomías del tercer mundo han crecido dramáticamente en los últimos treinta años, debido a la diversificación de actividades y a las estrategias de administración que ha alcanzado la población educada. Por supuesto, la transferencia de tecnología y la asistencia de los países desarrollados han desempeñado un papel crucial para lograr este objetivo.

Hoy, las instituciones de educación superior tienen la posibilidad de preparar a profesionales incluso en grados de maestría y doctorado; además cuentan con sus propios medios para la investigación. Las revistas de investigación científica incluyen obras de los países en desarrollo y las empresas multinacionales consideran a algunos de estos países como la mejor opción para sus 
URL: http://www.una.ac.cr/educare

CORREO: educare@una.cr

inversiones en el extranjero. Este aumento de la actividad económica y la subsiguiente demanda de gente educada representan un futuro muy optimista para los países en desarrollo como los de América Latina. En palabras de Bautista (2006), "(...) el desarrollo personal se identifica con el auténtico proceso educativo (...)” (p. 29). Aún así, no todo en este frenesí de educación universitaria es necesariamente positivo. Entre otras razones, se detallan las siguientes:

En primer lugar, la educación superior es considerada como un negocio atractivo y rentable: decenas de universidades privadas abren sus puertas en diferentes países sin la supervisión de las autoridades competentes, como una forma de certificar su calidad y reconocimiento. Como resultado, un gran número de nuevos graduados se incorpora cada año a la fuerza laboral solo porque tienen un diploma legal, aunque no certificado en cuanto a su calidad, de educación superior.

En segundo lugar, no todo tipo de conocimiento es comercializable en un "supermercado global". En otras palabras, como resultado de la imposición de las tendencias de la globalización, algunas asignaturas y carreras se consideran como "no productivas" o "no orientadas a la ganancia" y están siendo dejadas de lado. Temas relacionados con el humanismo, el pensamiento crítico, la responsabilidad social y ambiental, la ética, la moral y la fe se circunscriben a una preocupación muy particular, ya que no representan una contribución evidente a la economía del mercado hegemónico. Los estudiantes que cursan esas carreras con frecuencia reciben mensajes desalentadores sobre sus opciones de trabajo futuro.

En tercer lugar, dado que cada país del tercer mundo tiene una impagable deuda externa e interna, las instituciones financieras internacionales como el FMI y el Banco Mundial "recomiendan" que los gobiernos promuevan carreras "prácticas" y "técnicas" en vez de aquellas "teóricas" o "demasiado filosóficas". Por otro lado, las universidades privadas, como empresas lucrativas, tratan de encontrar nichos de mercado en las carreras de mayor demanda y de un alto nivel de empleo. Esta realidad está convirtiendo las instituciones de educación superior en talleres de formación dedicados a producir mano de obra calificada y obreros para mantener el estándar de vida de la gente del primer mundo. O bien, como lo afirma Díaz (2011) no se considera necesario que los nuevos profesionales se formen en un sistema educativo "dirigido a promover el desarrollo humano" (Díaz, 2011, p. 267).

Cuarto, las posiciones ideológicas de los profesores universitarios, investigadores y administradores, guiados por una interpretación un tanto extrema de la libertad de cátedra, impiden la posibilidad de lograr un consenso en cuanto a las políticas institucionales orientadas a diseñar proyectos académicos que, a largo plazo, beneficien a la nación y en los que los intereses de todos los grupos estén presentes. Lobato y De la Garza (2009) apuntan a ello como el "aislamiento" y la "soledad" en que trabajan los académicos. Por tanto, cada asignatura se imparte de manera que los alumnos tengan la total responsabilidad de hacer por sí mismos la síntesis vital de toda la información que adquieren en ellas.

Una carrera ha dejado de ser una carrera. Ahora es primordialmente el conjunto de cursos requeridos para obtener un diploma. Los cursos están organizados en un cierto orden lógico, pero no vinculados a las otras dimensiones que forman parte de la realidad humana de la persona 
en proceso de convertirse en profesional. En este sentido, los alumnos se capacitan para "hacer algo", y no tanto para "ser alguien". Por el contrario, Pasmanik y Winkler (2009) consideran que los estudiantes deben recibir ayuda en este proceso para que puedan darse cuenta de que las decisiones éticas son, en última instancia, personales y dependen de la conciencia individual. Por lo tanto, cada uno tiene que afrontar las consecuencias y los efectos de las medidas que tome.

Por último, pero no menos importante, las sociedades modernas, inspiradas en la tradición anglosajona de éxito individual, ejercen una fuerte presión sobre las instituciones de educación para cambiar la mentalidad de los alumnos de una perspectiva tradicional, cooperativa a otra moderna y competitiva. Este proceso comienza temprano en el jardín de niños y continúa a lo largo de los años de educación. Como resultado, los nuevos profesionales no parecen estar interesados en ayudar a resolver la desigualdad y las segregaciones de clase social en sus países. En lugar de eso, buscan instalarse cerca de los nuevos desarrollos comerciales y en los proyectos de vivienda en los suburbios, haciendo crecer las "ciudades privadas" en franca alienación de sí mismos con respecto a la cruda realidad de su país. Ignoran, o pretenden ignorar, que con los aportes de los contribuyentes de clase baja recibieron becas y estipendios para estudiar sus rentables carreras y alcanzar su envidiable comodidad. Bustamante (2009), presenta la situación de la manera siguiente:

Tal postura facilita los planteamientos que consideran que ayudar a los demás, a los más pobres y necesitados, no es más que una forma de promover la pereza, el vicio y una caridad o filantropía mal entendidas; acoge el hábito de analizar los problemas humanos desde los deseos caprichosos del individuo y no desde el punto de vista del bien de la comunidad humana; olvida la importancia de la sociedad en el desarrollo integral de la persona; y exalta la libertad de elección del individuo hasta prescindir de todo referente ético que lo oriente hacia su desarrollo integral. Incluso llega a omitir el cuidado del resto de la naturaleza, y olvida así que no se puede alcanzar un desarrollo humano, real y vivificador, si se prescinde de ella. Todo lo anterior, entre otros vicios que dificultan la construcción de una sociedad justa y bien cohesionada. (p. 41)

Es posible que una desviación del concepto original de la universidad pública y la educación superior, en general, estén en la base del crecimiento exponencial de la violencia, el descontento social y la deshumanización en los países del tercer mundo. Año con año, los gobiernos se jactan con informes de crecimiento económico, el control de la inflación y el aumento de las visitas turísticas. Esos informes evitan informar, concomitantemente, la creciente desigualdad y la necesidad de soluciones a largo plazo que se les están dejando a las generaciones futuras.

La preocupación ambiental, la salud, el tratamiento de la basura, el uso del suelo, la disponibilidad de agua potable, la erradicación de tugurios y otras realidades incómodas son postergados por parte de los gobiernos de turno. Los alumnos universitarios contemplan esta 
URL: http://www.una.ac.cr/educare

CORREO: educare@una.cr

innegable realidad y sueñan con obtener un buen trabajo y ganar suficiente dinero para escapar de la tragedia que corroe a otros sectores de la sociedad. En este momento, es conveniente recordar lo que la UNESCO (2009) propone: que la educación superior no solo debe dar sólidas habilidades para el presente y para el mundo futuro, sino también debe contribuir a la educación de ciudadanos éticos, comprometidos con la construcción de la paz, la defensa de los derechos humanos y los valores de la democracia.

En resumen, el crecimiento numérico de las instituciones de educación superior no garantiza el bienestar social y la calidad de vida de los ciudadanos. En cambio, la presión por ganar dinero para permitirse el lujo y la seguridad implica una fuerte dosis de estrés y ansiedad. Por cierto, estos dos síntomas parecen explicar el comportamiento consumista compulsivo y frenético de la gente de hoy. Es fácil suponer que las potencias comerciales están interesadas en el fortalecimiento de este frenesí.

\section{Más sociedades corruptas y más países gobernados por malos (aunque muy educados) administradores}

Basta ver los medios informativos para constatar que los países donde el estándar de vida es alto, como las del norte de Europa, son aquellos donde sus autoridades no se muestran tan frecuentemente en público. Por el contrario, en las naciones con los estándares más bajos, sus autoridades están constantemente en la televisión y otros medios, de lo cual América Latina y África abundan en ejemplos. En estos casos, ejercer cargos de presidencia, gobernación o de cualquier otra autoridad importante parece ser la forma de obtener beneficios materiales y la exaltación de su ego personal, algo que nunca sería alcanzable por otras vías. Los intentos para satisfacer ambiciones individuales a cualquier costo se multiplicaron con las tendencias de la globalización. Santos (1995) afirma que: cuando la economía de mercado se presenta como la panacea universal y el consumo es promovido como el único estilo de vida en los medios de comunicación, el concepto clave es la mercancía. Las élites económicas toman decisiones «correctas», en el momento "oportuno", según sus intereses. Esto genera una lógica implacable: todo debe convertirse en mercancía, todo tiene un precio. El único objetivo es la continua acumulación de riqueza.

Curiosa o lamentablemente, la mayoría de los líderes con extensos archivos de corrupción y abuso de autoridad, y nunca procesados por la justicia, son egresados de prestigiosas universidades nacionales o extranjeras. Resulta difícil creer que un día muchos estudiantes inteligentes, dotados de los más exclusivos -incluso de instituciones religiosas en primaria y secundaria- recursos de educación superior, terminan como líderes en partidos políticos que, en conspiración con las fuerzas económicas, manipulan las instituciones nacionales y establecen tiranías "legales" en las que su riqueza crece, exponencialmente, mientras la miseria y el sufrimiento de los ciudadanos pobres se ignora con total indolencia. Según Oppenheimer (2001), en América Latina, las conexiones políticas y los 'regalos' se han convertido en la clave del éxito económico, en lugar de la modernización de la empresa y los riesgos corporativos. 
¿Dónde está la majestad del Alma Mater, entonces? ¿Cómo es posible que las autoridades corruptas y toda clase de explotadores, agresores, contrabandistas y traficantes de drogas y de humanos, y una lista interminable de otros hacedores del mal estuvieran un día ocupando un lugar en nuestras aulas universitarias? Rodríguez (2010), comentando la obra de Bautista (2009) Etica para corruptos, enseña que, para este autor, la verdadera causa de la corrupción es la ignorancia, entendida no con respecto a contenidos culturales objetivos, sino como una incapacidad para prever las consecuencias de los actos antiéticos que se cometen. Bautista atribuye esta alteración de valores a la globalización, por haber roto la dimensión comunitaria de la sociedad y favorecido el individualismo, el relativismo moral y hasta el cinismo ante las estructuras de poder.

Por supuesto, entre los graduados de la universidad se cuenta también mucha gente honesta y consciente. Gracias a ellos las instituciones nacionales siguen avanzando y los grupos sociales mantienen esperanzas de un cambio positivo. Sin embargo, estos buenos ciudadanos son frecuentemente reacios a involucrarse en los partidos políticos, ya que la condición para ser bienvenido en tales agrupaciones es aceptar las normas establecidas por sus dirigentes, muchos de los cuales están comprometidos con intereses malsanos. También se niegan a cooperar en otras organizaciones comunales y hallar en ello gratificación personal. Por esa razón, incluso el creciente número de esas buenas personas no parece tener un impacto en el también creciente caos social.

De manera constante aumenta la brecha social y las expectativas de una nación, concebida como proyecto, a largo plazo parecen estar disipándose. Cansados de los abusos y las decepcionados por los mensajes de lujosas excentricidades procedentes de las groseras elites políticas y económicas, los ciudadanos de clase baja claman por el surgimiento de otro tipo de líder, que les preste atención a sus necesidades. Sobre esta base, varios países latinoamericanos han llevado al poder a varios líderes populistas en las últimas décadas. Todo esto ocurre sin que los miles de horas dedicadas al trabajo intelectual, la reflexión, la investigación y la producción de conocimiento hayan logrado ejercer un impacto eficaz. A lo sumo, publican periódicamente algunos artículos y otras reflexiones para unos destinatarios muy específicos.

Los formadores de opinión crítica no lograrán acceso a la mayoría del público. Las universidades mantienen su compromiso de formar a los nuevos profesionales y generar nuevos conocimientos, sin reparar en el tanto en que tales profesionales mejoran su calidad de vida total gracias a esos conocimientos. Los profesores universitarios necesitan recuperar su confianza en sí mismos para convertirse en modelos positivos para sus alumnos. Como lo afirma Findlow (2008):

La innovación académica puede ser socavada por las mismas cosas que socavan la satisfacción profesional general en la educación superior. Es decir, se mezclan mensajes sobre transparencia, incertidumbre ideológica y actitudes complejas ante el riesgo. (p. 326) ${ }^{3}$

3 Traducción del autor. 
URL: http://www.una.ac.cr/educare

CORREO: educare@una.cr

¿Si la educación superior promueve un comportamiento ético en estudiantes que inician sus estudios pletóricos de recta intención; pero, al mismo tiempo, tantos malhechores han sido universitarios, dónde podría haberse dado el cambio hacia lo negativo? En principio, como lo expresa KnapCzyk (2008), los seres humanos realizan acciones y sus acciones repetidas forman hábitos, estos son formas consistentes y automáticas que se siguen pasos para realizar una tarea.

Los hábitos modelan finalmente su opción en la vida, ya sea orientada a la armonía con los demás o dedicada a sacar provecho de ellos. Una mente brillante, por ejemplo, puede desarrollar hábitos en cualquier dirección. Un alma egoísta, al igual que una sensible y humanista, se cultiva mediante las acciones de la vida. Las primeras acciones conscientes y la formación de hábitos tienen lugar temprano en la infancia ${ }^{4}$.

Para el momento en que los estudiantes comienzan sus estudios universitarios, una gran cantidad de hábitos positivos y negativos van con ellos a clase también. En ese momento, los hábitos negativos, como hacer trampa en los exámenes o faltar a clases sin ningún motivo, podrían ser considerados, quizás, no lo suficientemente negativos como para indicar una tendencia a hábitos más perjudiciales que podrían conducir a un comportamiento corrupto en la futura vida profesional o laboral. Pero, de hecho, esta es la consecuencia de una primera etapa de malos hábitos adquiridos con anterioridad, con la indulgencia y aquiescencia de los padres y las instituciones educativas, por un lado, y la apertura a una etapa nueva de permanentes malas costumbres a lo largo de la edad adulta, por otro. En esta última, la búsqueda egoísta de las ambiciones individuales será la mayor preocupación de ese individuo. En adelante, alguien cuya opción fundamental sea impulsada por ese principio, aplicaría cualquier medio que fuera necesario para alcanzar sus afanes. Es por esta razón que tanto el antagonismo histórico entre el primer y tercer mundo, en un ámbito mundial, y las mezquindades de individuo a individuo, a escala local, pueden ser comprensibles, mas nunca justificables.

Las instituciones de educación superior suponen que cada nueva generación que se matricula en sus carreras ya ha logrado el equilibrio necesario en los dominios cognitivos y afectivos y es lo suficientemente madura como para centrarse en el contenido de las materias de la universidad. A continuación se reproducen las seis características que, según Allport (1968), citado por Bermeosolo (2010), constituyen una personalidad madura, con el fin de considerar si tales virtudes están presentes en los universitarios de hoy:

Amplia comprensión de sí mismo; capacidad de establecer relaciones emocionales con otras personas; fundamentos de seguridad emocional y aceptación de sí mismo; capacidad para percibir en profundidad, para pensar y actuar, de acuerdo con la realidad externa; capacidad para la percepción de sí mismo y sentido del humor; vivir en armonía, con una filosofía de una vida-unificada. (p. 68)

4 Para la formación de hábitos en la niñez, véase Miralles y Hernández (2009). 
¿Y los escollos de la vida que están sin resolver? ¿Exigen una disciplina igual todos los miembros del cuerpo docente para evitar mensajes contradictorios a los alumnos? ¿Los derechos y las obligaciones se entienden como realidades concomitantes?:Existe un entrenamiento adecuado en cuanto al pensamiento crítico de modo que los universitarios puedan discernir e interpretar los significados y los mensajes sutiles mediante los cuales los poderes económicofinancieros intentan abordarlos? Según Fitzmaurice (2008), "la capacidad de sintonizar con los estudiantes y conectarlos a ellos con el tema depende no solo de los métodos, sino también de la identidad y la integridad del maestro" (p. 347)

\section{La responsabilidad ética de profesores y alumnos por sus acciones individuales, hábitos y cosmovisión}

Si la educación superior pública es considerada como un derecho y un privilegio, y es financiada por todos los contribuyentes, también debe haber una responsabilidad derivada de esa cuenta. Los pueblos no solo invierten en educación para que su gente educada viva de ella. A diferencia del postulado fundamental del capitalismo económico financiero que está a la base de la globalización, donde la escasez es el principio regulador de las relaciones de producción, los propósitos reales de la educación pública deben ser la promoción, el diseño y el desarrollo de los medios por los cuales una sociedad reduzca sus brechas sociales y logre mejores estándares de vida para todos. Esto únicamente es concebible, si a los alumnos se les enseña de tal manera que se identifiquen con ese objetivo y si quienes enseñan son conscientes de su papel como modelos de lo que la sociedad necesita. Esto lo destaca Woolfolk (2004) como sigue:

La tendencia de la persona a desarrollar una conducta moral depende de la medida en que las creencias y los valores morales están integrados en la personalidad, así como en el sentido de sí misma. Por lo tanto, la influencia que tienen nuestras propias ideas morales en nuestras vidas está relacionada con la relevancia personal que, como individuos, les damos: Debemos respetarlas y asumirlas como nuestras. (p. 84)

Empezando por la responsabilidad de los docentes, debe decirse que se requiere más que de conocimiento de la materia y manejo de técnicas metodológicas para ser un docente eficaz. La mayor convicción que el personal docente debería compartir es que cada uno de sus alumnos es una persona real, con un proyecto de vida que debe ser diseñado y desarrollado con la orientación y ayuda de personas más experimentadas, entre las que están sus maestros. Por lo tanto, es normal que los alumnos esperen que sus profesores sean modelos de lo que enseñan.

5 Traducción del autor. 
URL: http://www.una.ac.cr/educare

CORREO: educare@una.cr

Un docente exitoso es tanto eficaz como responsable, como lo enseña Fitzmaurice (2008): "El desafío es integrar los dos conceptos en el desarrollo profesional" (p. 350$)^{6}$. En otras palabras, el maestro debe reflejar en sus acciones, así como en su discurso, que el contenido que enseña forma parte de un proyecto integral de la vida de sí mismo. Esto es lo que hace que valga la pena adquirir cualquier nuevo conocimiento. Los estudiantes perciben cuando un profesor está dando lo mejor de sí para proponer contenidos de aprendizaje significativo (Díaz Barriga y Hernández, 2002). Pero más allá de eso, aprenden acerca del docente a través de su actitud hacia ellos, hacia la institución y la sociedad. Los buenos educadores son también buenos modelos, inspirados en los cuales, los graduados dejan la universidad motivados a hacer de su profesión un compromiso con el proyecto de nación.

Por lo anterior, no importa cuán técnico o teórico sea un tema, siempre debe haber espacio para los enfoques inter-, trans- y multi- disciplinarios para la enseñanza. Al diseñar un plan de lección, por ejemplo, el profesor puede pensar en las formas por las que el tema estudiado se relaciona con otros temas, de modo que el alumno establezca asociaciones lógicas entre los diversos campos de conocimiento.

Al final de su etapa de formación inicial, este estudiante podrá realizar una síntesis vital de todo conocimiento en torno un centro único de significado, el cual es él mismo, entendiéndose siempre en relación armónica con los demás. Como dice KnapCzyk (2008), "los estudiantes que aprenden a utilizar sus habilidades de autodisciplina para alcanzar objetivos personales y externos llegarán a convertirse en auténticos directores de su propio comportamiento" (p. 166)7. Eso supondrá que las acciones positivas se conviertan en hábitos de enseñanza positivos.

Los docentes deben intentar comunicarse con sus colegas en forma regular, no solo para discutir formalidades y requisitos institucionales, sino también para compartir sus ideas y preocupaciones acerca de sus alumnos y el efecto que su enseñanza está teniendo en ellos como personas en crecimiento. De esta manera, los docentes pueden modelar su propia cosmovisión y adquirir un estado de conciencia que les inspire para superar las dudas y las vacilaciones en su propia vida. Se trata de la salud para los mismos profesores, la cual será una inspiración positiva para los alumnos también. Entenderán que pueden enfrentar los desafíos de la vida y que las ambiciones pueden alcanzarse con justicia, es decir, evitando aquellas acciones que, a la postre, traerán más molestias que la situación que originó la acción. Si la educación superior tuviera más docentes compartiendo estas ideas, los graduados universitarios probablemente dejarían las aulas para formar parte de la fuerza laboral con más honestidad, lealtad y calidad de vida.

En cuanto a la responsabilidad ética de los estudiantes, conviene decir que los hábitos, ya sea para bien o para mal, se pueden modificar en cualquier momento de la vida. Dependiendo del contexto y de otros factores, los buenos hábitos pueden degenerar en malos y los malos hábitos pueden sustituirse por buenos.

\footnotetext{
6 Traducción del autor.

7 Traducción del autor.
} 
Se espera que la educación formal sea un entorno en el que se promuevan los buenos hábitos, mientras que los malos se dejen atrás gracias a la madurez, la responsabilidad y la inspiración. La mala noticia aquí es que, en las instituciones de educación superior, esas virtudes simplemente se consideran ya adquiridas, o bien, se posponen para otros tiempos, dado que la presión por el contenido del aprendizaje y la urgencia de pasar los cursos y obtener un título y encontrar un empleo y ser promovido y hacer más dinero y... no deja que los alumnos reflexionen acerca lo que va mal en sus vidas. Así, las personas se acostumbran a vivir o coexistir con esas dimensiones oscuras de su personalidad y mantienen la ilusión de que un día en el futuro esas sombras desaparecerán ${ }^{8}$. Pasa el tiempo y, en su lugar, las malas acciones traerán consigo más malas acciones. Según Bermeosolo (2010), de un niño, un joven o un adulto que no ha alcanzado el nivel de logros que se espera de él, se dice que es inmaduro.

Para modificar los malos hábitos, la disciplina es imprescindible. Los estudiantes que crecieron en un ambiente permisivo esperarán que todo el mundo tolere sus acciones en cualquier momento y en cualquier lugar. Por desgracia, en la vida real, con frecuencia, tienen que aprender de la manera más difícil, las calles y los lugares de trabajo, donde los empleadores no son necesariamente indulgentes.

En la universidad, los simples malos hábitos de la infancia y de la escuela secundaria pueden conducir a otros malos hábitos: como aprovecharse de otras personas, esgrimir excusas para no presentar tareas, no asistir a clases o mantener un rendimiento mediocre. Aquí los profesores desempeñan un papel en el mantenimiento de la disciplina y los estándares universitarios. Como se indica en el párrafo anterior, el modelo y la motivación son el secreto para formar alumnos comprometidos con un buen desempeño. Es crucial que los estudiantes sepan que no solo estudian para obtener un diploma, encontrar un trabajo y obtener un estatus social, aunque parezca que las carreras están diseñadas para esos fines. La relación de profesores y alumnos debe llegar a un punto de negociación e interpretación de significados que cada tema de discusión y cada nuevo conocimiento que se les propone a los alumnos, pueda caber en un espectro más amplio de conocimientos, de los cuales el estudiante pueda apropiarse.

Un alumno capacitado para ubicar el conocimiento en la dimensión adecuada dentro de su proyecto de vida, difícilmente, desarrollará una cosmovisión egoísta. Esos estudiantes tendrán más probabilidades de buscar la felicidad y la realización personal, conscientes de que forman parte de la sociedad. Una vez que se gradúen y empiecen a trabajar, serán lo suficientemente maduros como para discernir lo que es mejor para ellos y lo que se necesitan para obtener lo que quieren. La ambición y la codicia son comunes a todas las personas; sin embargo, la gente educada puede tener suficientes criterios para tomar decisiones responsables. También pueden considerar lo que tienen que sacrificar para conseguir algo. Si esta consideración se convierte en un hábito, toda su vida será mucho más armoniosa.

$8 \quad$ Al respecto de la educación emocional, véase Bisquerra-Alzina (2006). 
URL: http://www.una.ac.cr/educare

CORREO: educare@una.cr

Aunque la idea de un materialismo inevitable de las sociedades modernas, liderado por la economía globalizada, está ampliamente difundida, la verdad es que las personas aún deben concebirse como los dueños de sí mismos. La obediencia a las campañas publicitarias, la avaricia y hábitos para impresionar a los demás, todos en grado compulsivo, no son constituyentes necesarios de la naturaleza humana. Tales comportamientos son desarrollados por algunos individuos de cada generación "mal-educados" para pensar así y actuar en consecuencia.

La educación superior está patrocinada por toda la sociedad, cuyo núcleo y esencia demandan espacios posibles para que los seres humanos se desarrollen con dignidad y armonía. Algunas personas piensan que la corrupción es parte de la naturaleza humana. Dado que ser corrupto es un comportamiento común tolerado en estos días, es posible entender a quienes piensan que lo es. En realidad, cada ser humano puede ser educado para elegir el bien y evitar el mal; en otras palabras, "otro mundo es posible". Según eso, el principal compromiso de las universidades en el siglo XXI no es preparar a los trabajadores altamente calificados para servir a los intereses de las empresas multinacionales, ni la producción de nuevos conocimientos para servir a esos mismos intereses o los intereses de quienes disfrutan de la afición del aprendizaje patrocinado por los impuestos de los trabajadores. El principal compromiso de la educación superior es formar a los seres humanos en armonía con su dignidad intrínseca y propiciar los medios por los cuales sus vidas, así como la vida de sus vecinos, puedan crecer conforme a esa dignidad. Según Watson (2007), "las universidades y colegios, pueden escoger comportarse bien o mal y depende de nuestros intereses tanto sociales como morales el ayudarles a elegir lo primero" (p. 373) ${ }^{10}$.

\section{En busca del principio y fundamento de una "Weltanschauung" o visión del mundo para la gente con educación superior}

Se dice que la educación es la única esperanza para cambiar las prácticas corruptas en el mundo. También se dice que ese cambio toma tiempo. Las instituciones de educación superior; sin embargo, están llamadas a formar a nuevos profesionales que, con el tiempo, van a guiar las generaciones en una renovada Weltanschauung o cosmovisión y según el Zeitgeist o espíritu de los tiempos. Estos dos conceptos, tomados de la lengua alemana, nos ayudarán a representar las formas a través de las cuales quienes están involucrados en la educación superior conducirán a nuevas ideas y voluntad de hacer uso del conocimiento universal a favor de la humanidad entera, en lugar de usarlo para explotar y aprovecharse unos de los otros, como es el caso hoy.

Según Palacio (2005), se entiende por Weltanschauung la cosmovisión, es decir, la manera, tanto individual como colectiva, en que se concibe el mundo. Puede que esta cosmovisión esté centrada en uno mismo o en armonía con los demás y con el entorno. En el primer caso, cada acción humana se rige por un principio egoísta de éxito individual

\footnotetext{
9 Véase el documental Memoria del saqueo (Solanas, 2003).

10 Traducción del autor.
} 
que mantiene una expectativa teórica de beneficio colateral para otros, una vez que se han alcanzado extremos individuales. De acuerdo con esta tendencia, también está implícita una inevitable necesidad de sacrificar el medio ambiente y hacer del mundo un lugar hostil para sí y para los otros. Tal visión del mundo se ha desarrollado debido a una mentalidad de conseguir, a corto plazo, el mayor beneficio posible, sin importar demasiado las consecuencias futuras. Muchas universidades se han adherido a esta concepción de progreso y de éxito. El pensamiento occidental ha sido gobernado, en buena medida, también por ese principio. Sin embargo, la ampliación de la brecha en términos de desigualdad entre grupos humanos muestra el fracaso evidente de esa tendencia. Las enseñanzas y publicaciones de los académicos que comparten esa filosofía del progreso, ejercen una fuerte influencia en sus estudiantes y lectores. Probablemente, estén convencidos de que ese es el camino correcto, pese a los datos de una realidad innegable.

En el segundo caso, aún reconociendo que el progreso del mundo es naturalmente impulsado por la ambición individual, nada debe aceptarse como auténtico progreso cuando en el proceso de su consecución se han ultrajado los derechos de otros individuos. Según esta visión, el éxito individual no se logra adecuadamente mediante la manipulación de otros como manera de realizar sus metas personales. En cambio, se considera que cada individuo es talentoso de alguna manera y puede desarrollar un proyecto de vida personal en el que las metas solo se pueden alcanzar satisfactoriamente, si los efectos -tanto personales como colectivos, globales y ambientales- pueden ser compensados.

Quienes comparten esta Weltanschauung están dispuestos a apoyar iniciativas como la tolerancia, la promoción de los derechos humanos, las sociedades inclusivas y la disponibilidad de conocimientos; pero, también, defienden la necesidad de crear condiciones económicas como el empresariado local y las inversiones extranjeras en las que las oportunidades de trabajo aumenten en número, así como en la humanización de las condiciones de quienes trabajan, la distribución de la riqueza, el desarrollo comunitario y la defensa de los recursos naturales y el hábitat. Esto solo es posible con la decisiva contribución de los profesionales de todas las áreas comprometidas con la idea de un mundo mejor para todos, no con la idea de "esnob" y de un gueto excluyente dentro de las ciudades, como es el caso en muchos países de América Latina. Esta visión del mundo debe ser educada. Implica el cultivo positivo de una escala de valores. Según López de Llergo (2005), los valores son perfecciones naturales todavía no adquiridas que pueden, sin embargo, convertirse en principios y normas. Estas perfecciones suscitan hábitos que, al tiempo, se manifiestan en conductas, buenas o malas, dependiendo de la calidad moral de los hábitos. Por lo tanto, los hábitos son el eje de la educación.

Una Weltanschauung o cosmovisión, según una perspectiva humanista, puede y debe ser motivada y cultivada en las instituciones de educación superior. Esta es la única forma de conseguir que quienes toman las decisiones y definen las políticas conciban la nación como un proyecto permanente. Con este objetivo, es importante definir un principio fundamental que inspire tal cosmovisión. Recordando la idea presentada en la introducción de este documento, 
URL: http://www.una.ac.cr/educare

CORREO: educare@una.cr

la educación formal se declaró como un privilegio, algo que no debe darse por sentado. Por ello, se propone aquí que tal principio lo constituye la gratitud, la cual, según Froh, Bono y Emmons (2010), es una respuesta positiva a recibir un beneficio.

Las personas reciben educación no solo para llevar a cabo sus tareas de trabajo sino, y ante todo, para articular su vida como un proyecto personal e integral y, a la vez, desarrollar un sentimiento de gratitud con el cual se dispongan a construir un conjunto estable de principios, gobernado por la honestidad, la ética y la buena voluntad. Se dice también que la gratitud posee tres características psicológicas muy importantes para procesar y responder al comportamiento pro-social. Para McCollough, Kimeldorf y Cohen (2008), esas características son:

a) [Ser] detector de beneficio, b) [generar] reforzamiento c) [actuar como] motivador del comportamiento pro-social. (p. 152)

Si ese principio estuviera presente como eje trasversal en cada propuesta curricular en las carreras universitarias, y fuera compartido por maestros, autoridades, investigadores y estudiantes, las instituciones de educación superior, definitivamente, harían una diferencia en la calidad humana de los graduados que envían a la sociedad para ser incorporados en la fuerza laboral.

\section{Conclusión}

Este trabajo fue inspirado por una preocupación racional y bien sustentada acerca de la realidad enfrentan los países de América Latina, una realidad que incluso ha empeorado en las últimas dos décadas: la corrupción en gente educada. Se dijo que la educación formal está destinada a preparar a las personas no solo para obtener empleos calificados, sino también para ayudarles a ser mejores seres humanos. Se destacó que el principal compromiso de la educación superior no es con un privilegio para un pequeño grupo de la sociedad, aquellos que adquieran una ventaja comparativa y alcancen una mejor posición, comparados con aquellos a quienes se les negaron esas oportunidades.

El compromiso de la educación superior es, más bien, promover el desarrollo inclusivo de toda la sociedad, a cambio del sacrificio que implica la inversión en educación. Se presentaron varios ejemplos de corrupción en personas educadas, junto con una reflexión sobre cómo la instrucción positiva, inspirada por intenciones honestas no ha podido evitar que muchos graduados universitarios hayan cedido a favor de prácticas egoístas y de corrupción.

Cultivar el valor de la gratitud fue, entonces, propuesto como el principio que inspira en las personas una decisión permanente de mantener sus acciones y hábitos bien cerca de su proyecto personal de realización humana. La gratitud ha de considerarse, pues, no como un 
valor, sino como una virtud que, de acuerdo con López de Llergo (2005), es un buen hábito que se ha integrado en la personalidad de manera permanente.

Las futuras investigaciones en este campo pueden incluir estudios de casos sobre cómo los estudiantes de la Universidad pueden ser motivados y entrenados para cultivar este principio en sí mismos y también en los profesores e investigadores.

\section{Referencias}

Acevedo, L. J. y Rodríguez, P. A. (junio, 2008). Panem et Circenses, ¿educación de calidad o redistribución? Efectos de la provisión de un bien privado y su calidad por parte del sector público sobre el crecimiento y la distribución del ingreso. Revista de Economía del Rosario, 11(1), 105-120. Recuperado de http://www.urosario.edu.co/urosario_files/d9/d9d3d447ef69-475f-a684-5b8f442def5a.pdf

Bustamante, R. (2009). Respuestas al individualismo exacerbado y al pensamiento postmoderno, a propósito de los derechos humanos. Derecho PUCP, 63, 37-55. Recuperado de http:// revistas.pucp.edu.pe/index.php/derechopucp/article/view/2940/2853

Rodríguez, J. (setiembre-diciembre, 2010) ¿Los corruptos aprenden ética? Orientaciones éticas para atajar la corrupción. Convergencia: Revista de Ciencias Sociales, 17(54), 201-208. Recuperado de http://redalyc.uaemex.mx/pdf/105/10514641010.pdf

Bautista, J. M. (2006). Educar en la postmodernidad. Descubrir personas y orientar su desarrollo. San José, Costa Rica: EUNED.

Bermeosolo, J. (2010). Psicopedagogía de la diversidad en el aula. Desafío a las barreras en el aprendizaje y la participación. México: Alfaomega.

Bisquerra-Alzina, R. (2006). Orientación psicopedagógica y educación emocional. Estudios sobre educación (ESE), 11, 9-25. Recuperado de http://hdl.handle.net/10171/9208

Lobato, O. y De la Garza, E. (enero-marzo, 2009). La organización del cuerpo académico: Las premisas de decisión, colegialidad y respuesta grupal. Revista Mexicana de investigación educativa (RMIE), 14(40), p. 191-216. Recuperado de http://scielo.unam.mx/pdf/rmie/v14n40/ v14n40a10.pdf

Díaz-Barriga, F. y Hernández, G. (2002). Estrategias docentes para un aprendizaje significativo. Una interpretación constructivista (2ªd.). México: McGraw-Hill.

Díaz, R. (2011). Desarrollo sustentable. Una oportunidad para la vida (2a Ed.). México: McGraw-Hill.

Escofet, A., García, I. y Gros, B. (2011). Las nuevas culturas de aprendizaje y su incidencia en la educación superior. Revista Mexicana de Investigación Educativa, 16(15), 1177-1195. Recuperado de http://redalyc.uaemex.mx/redalyc/pdf/140/14019203008.pdf 
URL: http://www.una.ac.cr/educare

CORREO: educare@una.cr

Findlow, S. (junio, 2008). Accountability and innovation in higher education: a disabling tension? [Rendición de cuentas e innovación en la educación superior: una tensión limitante]. Studies in Higher Education, 33(3), 313-329. Recuperado de http://www.siduna.una.ac.cr:2384/ ehost/pdfviewer/pdfviewer?vid=3\&sid=247ef8d6-9014-4fc5-80f5-e5423be51e90\%40sessi onmgr4\&hid $=6$

Fitzmaurice, M. (2008). Voices from within: Teaching in higher education as a moral practice. [Voces desde adentro: enseñanza en la educación superior como una práctica moral]. Teaching in Higher Education, 13(3), 341-352. Recuperado de http://www.siduna.una. ac.cr:2384/ehost/pdfviewer/pdfviewer?vid=3\&sid=e3cf771b-fd28-40f8-bd52-a369e2fbd8 58\%40sessionmgr15\&hid $=6$

Froh, J., Bono, G. y Emmons, R. (2010). Being Grateful is beyond Good Manners [Ser agradecido va más allá de buenos modales] Motivation y Emotion, 34(2), 144-157. Recuperado de http:// www.siduna.una.ac.cr:2384/ehost/pdfviewer/pdfviewer?vid=3\&sid=e3cf771b-fd28-40f8bd52-a369e2fbd858\%40sessionmgr15\&hid=101

KnapCzyk, D. (2008). Guía de autodisciplina. ¿Cómo transformar los problemas de conducta en objetivos de autodisciplina? Madrid: Nárcea.

López de Llergo, A. T. (2005). Educación en valores, educación en virtudes. México: CECSA.

McCollough, M. E., Kimeldorf, M. B. y Cohen, A. D. (2008). An Adaptation for Altruism? The Social Causes, Social Effects, and Social Evolution of Gratitude. [Una adaptación del altruismo? Las causas, efectos y direcciones actuales de la evolución social de la gratitud] Current Directions in Psychological Science, 17(4), 281-285. Recuperado de http://www.psy.miami.edu/faculty/mmccullough/Papers/Gratitude_CDPS_2008.pdf

Miralles, D. y Hernández, S. (2009). El arte de la educación infantil. Guía práctica con niños de 0 a 6 años. Madrid: Nárcea.

Oppenheimer, A. (2001). Ojos vendados. Estados Unidos y el negocio de la corrupción en América Latina. Buenos Aires: Editorial Sudamericana.

Palacio, M. D. (2005). Vida y mundo: Reflexiones a partir de Dilthey y Husserl. Cuadernos de filosofía Latinoamericana, 26(92), 139-153. Recuperado de http://www.siduna.una.ac.cr:2384/ehost/ pdfviewer/pdfviewer?vid=7\&sid=e3cf771b-fd28-40f8-bd52-a369e2fbd858\%40sessionmg r15\&hid=101

Pasmanik, D. y Winkler, M. I. (noviembre, 2009). Buscando orientaciones: Pautas para la enseñanza de la ética en psicología en un contexto con impronta postmoderna. Psykhe, 18(2), 37-49. Recuperado de http://redalyc.uaemex.mx/src/inicio/ArtPdfRed.jsp?iCve=96711850003

Santos, N. (1995). Ética y corrupción. México: Artes gráficas Silva. 
Solanas, M. M. (Productora asociada), Solanas, P. (Director), Solanas, P. (Guionista). (2003). Memoria del saqueo [Documental]. Argentina: Sinesur S. A. Recuperado de http://www.youtube. com/watch?v=CyTkn376dWo

UNESCO. (2009). Conferencia mundial sobre la educación superior. "La nueva dinámica de la educación superior y de investigación para el cambio social y el desarrollo". Comunicado. París: Autor. Recuperado de http://unesdoc.unesco.org/images/0018/001832/183277s.pdf

Watson, D. (2007). Does Higher education Need a Hippocratic Oath? [¿La educación superior necesita un juramento hipocrático?] Higher Education Quarterly, 61(3), 362-374. doi: 10.1111/j.1468-2273.2007.00359.x

Woolfolk, A. (2004). Psicología educativa (9a Ed.). Ohío: McGraw-Hill.

\section{Cómo citar este artículo en APA:}

Barrantes, L. G. (2013). Responsabilidad ética de educadores y educandos desde una perspectiva humanista. Revista Electrónica Educare, 17(1), 29-45. Recuperado de http:// www.revistas.una.ac.cr/index.php/EDUCARE/issue/current

Nota: Para citar este artículo en otros sistemas puede consultar el hipervínculo "Como citar el artículo" en la barra derecha de nuestro sitio web:

http://www.revistas.una.ac.cr/index.php/EDUCARE/index 